\title{
OURICURI
}

\section{UTILIZAÇÃO DE BACTÉRIAS NO CONTROLE DE FUNGOS FITOPATOGÊNICOS IN VITRO}

\author{
Mariana Santana de JESUS ${ }^{1}$, Poliana Gonçalves GUIMARÃES²
}

\author{
${ }^{1}$ Graduanda em Engenharia Agronômica; jesusmarianasantana@hotmail.com; \\ 2Professora do Departamento de Ciências Humanas e Tecnologias, Campus XXII, Euclides da Cunha -BA, \\ pgguimaraes@uneb.br \\ http://doi.org/10.29327/ouricuri.v8.i1.a5
}

Resumo: $O$ presente trabalho objetivou verificar o potencial de rizobactérias de cactáceas na inibição do crescimento de Fusarium solani in vitro. O experimento foi realizado no Laboratório de Microbiologia do Semiárido - LAMSA, na UNEB, campus XXII de Euclides da Cunha-BA. Foi analisado 0 antagonismo entre o fungo Fusarium solani e 11 rizobactérias de cactáceas (Tacinga palmadora e Melocactus zehntneri). Em uma placa de Petri com meio de cultura BDA solidificado, foi adicionado um disco com micélios do patógeno no centro, e em quatro pontos distantes (ao redor da placa) foram feitas estrias com a bactéria selecionada, havendo três repetições para cada tratamento, e três placas de testemunha contendo apenas o fungo. $O$ fungo foi analisado durante 10 dias (período necessário para que as colônias testemunhas ocupassem toda a placa), com a medição do diâmetro das colônias, onde foram retiradas as médias de duas medidas diametralmente opostas a cada $24 \mathrm{~h}$. Os resultados obtidos na primeira etapa mostraram que das 15 bactérias testadas, apenas 11 poderiam ser utilizadas nos testes posteriores, destas 11 bactérias cinco foram eficientes no controle do patógeno. Pode-se concluir que as bactérias oriundas da cactácea Tacinga palmadora P2.2, P6.2, P10.2, P12,2 e a P13.2 foram as que conseguiram inibir mais efetivamente o fungo testado, sendo que a P6.2 foi a que obteve um melhor resultado estatístico.

Palavras-chave: Cactáceas; Doenças; Rizobactérias; Biocontrole; Fusarium solani.

\section{USE OF BACTERIA IN THE CONTROL OF IN VITRO PHYTOPATOGENIC FUNGUS}

\begin{abstract}
The objective was to verify the potential of cactaceae rhizobacteria in inhibiting the growth of Fusarium solani in vitro. The experiment was carried out at the Laboratory of Microbiology of the Semiarid-LAMSA, at UNEB, campus XXII of Euclides da Cunha-Ba. The antagonism between the fungus Fusarium solani and 11 cactaceous rhizobacteria (Tacinga palmadora and Melocactus zehntneri) was analyzed. In a Petri dish with BDA culture medium, a disk was added with mycelia of the pathogen in the center, and at four distant points (around the plate) 1 stria was made with the selected bacterium, with three replicates for each treatment, and three plates containing only the fungus, to be the control. The development of the fungus was analyzed during 10 days, with the measurement of the diameter of the colonies, where the means of two diametrically opposite measurements were verified every $24 \mathrm{~h}$. The results obtained in the first step showed that of the 15 bacteria tested, only 11 could be used in the subsequent tests, of these 11 bacteria 5 were efficient in controlling the pathogen. It can be concluded that the bacteria from the cactus Tacinga palmadora $\mathrm{P} 2.2, \mathrm{P} 6.2, \mathrm{P} 10.2, \mathrm{P} 12.2$ and P13.2 were the ones that were able to inhibit the fungus more effectively tested, being that $P 6.2$ was obtained a better statistical result.
\end{abstract}

Key words: Cactaceae; Diseases; Rhizobacteria; Biocontrol; Fusarium solani.

Revista Ouricuri, Juazeiro, Bahia, v.8, n.1. p.048-056.jan./jun., 2018. http://www.revistas.uneb.br/index.php/ouricuri | ISSN 2317-0131 


\section{INTRODUÇÃO}

Sabe-se que, em todos os lugares do mundo onde se pratica agricultura econômica, o controle de doenças de plantas é largamente realizado por meio de pesticidas (KIMATI et al., 1997). Segundo Bettiol (1991), o biocontrole pode ser conseguido através de práticas que favoreçam os antagonistas nativos ou através da introdução no solo de microrganismos selecionados cultivados em substratos no solo.

O Fusarium solani é um fitopatógeno habitante do solo, importante agente causador de doenças de diversos cultivos, tais como podridão de raiz, de frutos de Cucurbita spp., de ervilha, do pé de feijão, do colo e raízes em maracujá, síndrome da morte súbita da soja e podridão seca de batata, esse fungo é importante devido aos danos econômicos causados no setor agrícola e por sua distribuição cosmopolita (GHINI e NAKAMURA, 2001). A infecção com Fusarium começa inicialmente com a entrada do fungo nas raízes mais jovens e secundárias pela coifa, além de aberturas naturais e ferimentos, levando a apresentar sintomas de podridão do colo nos estágios mais avançado da infecção (TREMACOLDI, 2010; AMORIM et al., 2011). Este patógeno produz toxinas virulentas (naftoquinonas e ácido fusárico) que são capazes de matar a célula hospedeira ou desativar suas funções (SINGH et al., 1981; CREPPY, 2002; PASCHOLATI, 2011).

As rizobactérias são microrganismos que estão presente na rizosfera e que colonizam o sistema radicular, cerca de 7 a 15\% da superfície total das raízes é ocupada por estas células microbianas, atuando diretamente nas plantas ou nos substratos (SCHROTH e HANCOCK, 1982; GRAY e SMITH, 2005), esses microrganismos são atraídos devido a liberação de exsudatos das plantas, como os aminoácidos, ácidos orgânicos, carboidratos, além de outras substâncias (SESSITSCH et al., 2013).

Esses microrganismos existentes no solo estão envolvidos na síntese de auxinas em meio de cultura e no solo (ANTOUN et al., 1998; VEGA-HERNÁNDEZ et al., 2002). Além disso, as estirpes bacterianas colaboram indiretamente no desenvolvimento das plantas a partir da fabricação de vários antibióticos ou outros mecanismos de biocontrole, onde dificultam o desenvolvimento de vários microrganismos considerados fitopatogênicos (DASHTI, 1998; GRAY e SMITH, 2005).

Vários estudos estão sendo realizados com controle biológico e a utilização de rizobactérias tem proporcionado defesa no controle de fitopatógenos de solo (WELLER, 1988). O controle biológico se tornou uma excelente alternativa para ser utilizado na agricultura, visto que pode ser utilizado para a proteção contra esses organismos, além ainda de diminuir a utilização de agrotóxico na agricultura (PERES et al., 2007; BONFIM et al., 2010).

Visto que o Fusarium é um poderoso fitopatógeno e que a utilização de produtos químicos para combatê-lo pode causar inúmeros problemas ambientais, viu-se a possibilidade da utilização de rizobactérias de cactáceas contra o crescimento do $F$. solani, dado o potencial destas de atuarem como uma barreira à penetração de patógenos. Sendo assim, este trabalho teve como objetivo

Revista Ouricuri, Juazeiro, Bahia, v.8, n.1. p.048-056.jan./jun., 2018. 
verificar o potencial de rizobactérias de cactáceas na inibição do crescimento de Fusarium solani in vitro.

\section{METODOLOGIA}

O experimento foi realizado no Laboratório de Microbiologia do Semiárido - LAMSA, localizado na Universidade do Estado da Bahia - UNEB, Departamento de ciências Humanas e Tecnologia - DCHT campus XXII de Euclides da Cunha-Ba.

O fungo Fusarium solani utilizado foi isolado de maracujazeiro e mantido no Laboratório de Fitopatologia da Universidade Estadual do Sudoeste da Bahia - UESB, Campus de Vitória da Conquista, até ser doado para a UNEB, e assim iniciarmos este experimento. As bactérias foram extraídas da rizosfera de Tacinga palmadora, isolados P2.2, P3.2, P4.2, P6.2, P7.2, P8.2, P9.2, P10.2, P11.1, P12.2 e P13.2 e Melocactus zehntneri, isolados CF17.2 CF18.2, CF19.2 e CF20.2, obtidas de trabalhos anteriores e mantidas no LAMSA, até a sua utilização.

Foram analisadas 15 bactérias e testadas a viabilidade das mesmas em meio BDA (Batata, dextrose e ágar). Após esta seleção (Tabela 1), foi analisado o antagonismo entre o fungo e as 11 rizobactérias selecionadas (Figura 1).

Tabela 1. Análise do desenvolvimento das rizobactérias de Tacinga palmadora (P2.2, P3.2, P4.2, P6.2, P7.2, P8.2, P9.2, P10.2, P11.1, P12.2 e P13.2) e Melocactus zehntneri (CF17.2 CF18.2, CF19.2 e CF20.2) em meio BDA.

\begin{tabular}{|c|c|c|c|}
\hline \multirow[b]{2}{*}{ Bactérias } & \multicolumn{3}{|c|}{ CLASSIFICAÇÃO } \\
\hline & Excelente $^{*}$ & Bom $^{\star *}$ & Ruim $^{\star \star *}$ \\
\hline P2.2 & $X$ & & \\
\hline P3.2 & & & $X$ \\
\hline P4.2 & & & $x$ \\
\hline P6.2 & $x$ & & \\
\hline P7.2 & $x$ & & \\
\hline P8.2 & & $x$ & \\
\hline P9.2 & & $x$ & \\
\hline P10.2 & & $x$ & \\
\hline P11.2 & $x$ & & \\
\hline P12.2 & $x$ & & \\
\hline P13.2 & $x$ & & \\
\hline CF17.2 & & $x$ & \\
\hline CF18.2 & & & $x$ \\
\hline CF19.2 & & & $x$ \\
\hline CF 20.2 & $X$ & & \\
\hline
\end{tabular}

${ }^{*}$ Se desenvolveu dentro de $24 \mathrm{~h}$. ${ }^{* \star}$ Se desenvolveu dentro de $48 \mathrm{~h}$. ${ }^{* * *}$ Não se desenvolveu, ou houve pouco desenvolvimento até as $48 \mathrm{~h}$.

Revista Ouricuri, Juazeiro, Bahia, v.8, n.1. p.048-056.jan./jun., 2018. 
Em uma placa de Petri com $20 \mathrm{ml}$ de meio de cultura BDA solidificado, foi adicionado um disco com 0,5 cm de BDA com micélios de Fusarium solani ao centro, e em quatro pontos distantes (ao redor da placa) foram feitas estrias (Figura 2) com a bactéria selecionada, com três repetições para cada tratamento, e três placas testemunha contendo apenas o fungo.

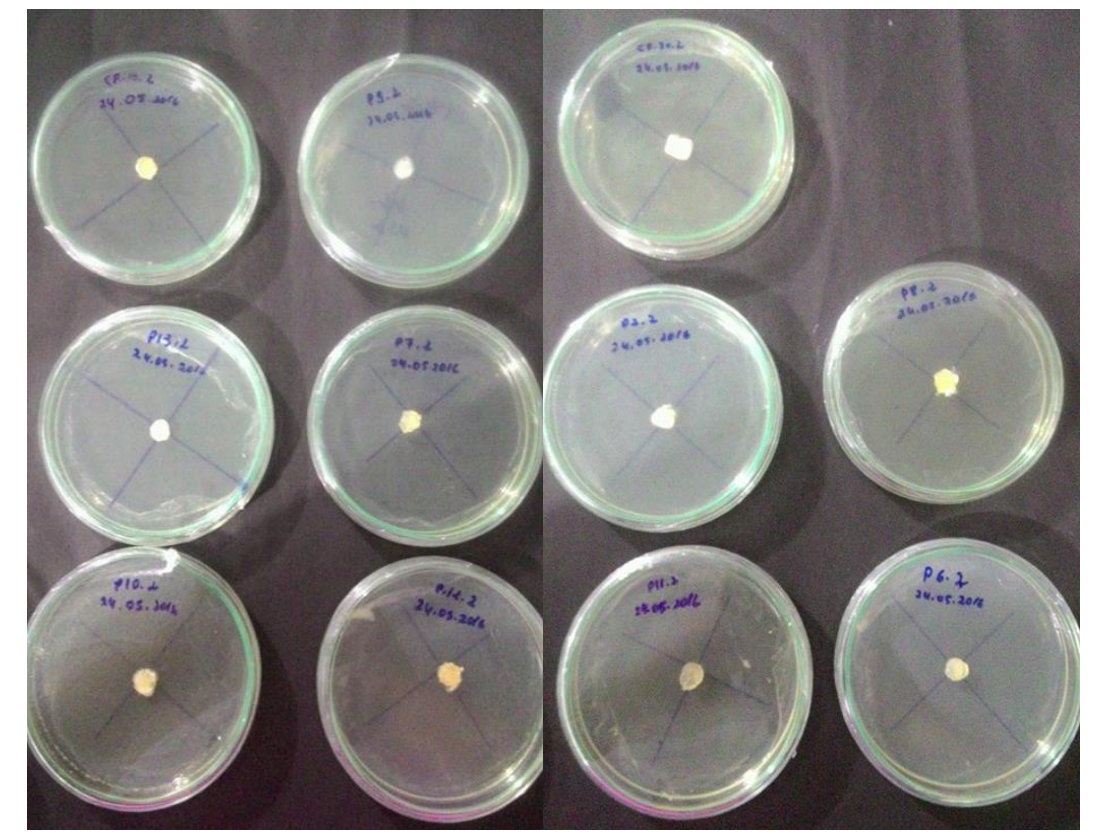

Figura 1. Primeiro dia de análise do fungo $F$. solani (no centro da placa) com as 11 rizobactérias selecionadas. Fonte: JESUS, M. S.

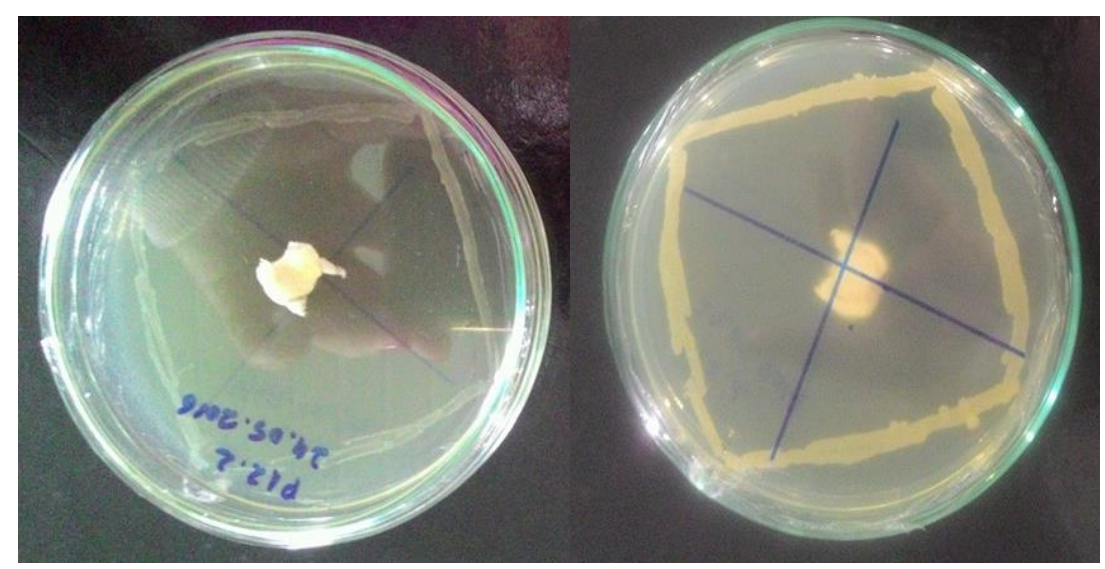

Figura 2. Método de disposição das bactérias nas placas, com quatro estrias por placa e o fungo ao centro. Fonte: JESUS, M. S.

O desenvolvimento do Fusarium solani foi analisado durante 10 dias, sendo realizadas medições do diâmetro das colônias em dois sentidos diametralmente opostos, com auxílio de uma régua milimétrica, definindo-se uma média para cada colônia. As medições dos diâmetros das colônias começaram a ser realizadas $24 \mathrm{~h}$ após a inoculação do patógeno e da rizobactéria, até que as placas contendo o fungo controle fossem totalmente colonizadas. 
O delineamento experimental adotado foi o inteiramente casualizado (DIC), com 11 tratamentos e quatro repetições. Os resultados foram submetidos à análise de variância pelo teste de $\mathrm{F}$, e em caso de significância as médias foram comparadas pelo teste de Scott-Knott a 5\% de significância.

\section{RESULTADOS E DISCUSSÕES}

Os resultados obtidos na primeira etapa mostraram que das 15 bactérias testadas, apenas 11 poderiam ser utilizadas nos testes posteriores, já que estas obtiveram uma boa taxa de crescimento em meio BDA, onde foram classificadas como bom e excelente (Tabela 1).

$\mathrm{Na}$ segunda etapa do experimento, houve diferença estatística entre as bactérias para todos os dias testados desde o $3^{\circ}$ ao $10^{\circ}$ dia de análise, onde houve a interação do fungo Fusarium solani com as bactérias (Tabela 2). Observou- se que a bactéria P6.2 (identificada como Bacillus) foi a que exerceu o melhor controle do desenvolvimento do fungo, quando comparado com a testemunha (Figura 3), esta bactéria conseguiu inibir o fungo do $3^{\circ}$ até o $10^{\circ}$ dia de inoculação (Tabela 3).

Tabela 2. Análise de variância do diâmetro de colônia $(\varnothing \mathrm{C})$ em $\mathrm{cm}$, do fungo Fusarium solani in vitro, do $1^{\circ}$ ao $10^{\circ}$ dia em função das fontes de variações (FV) das bactérias (B), grau de liberdade (GL) e do quadrado médio (QM).

\begin{tabular}{|c|c|c|c|c|c|c|c|c|c|c|c|}
\hline \multirow{2}{*}{$\begin{array}{l}\text { FV } \\
\varnothing \mathrm{C} / \text { Dia }\end{array}$} & \multirow[t]{2}{*}{$\mathrm{GL}$} & \multicolumn{10}{|c|}{ QM } \\
\hline & & $1^{\circ}$ & $2^{\circ}$ & $3^{\circ}$ & $4^{\circ}$ & $5^{\circ}$ & $6^{\circ}$ & $7^{\circ}$ & $8^{\circ}$ & $9^{\circ}$ & $10^{\circ}$ \\
\hline$B$ & 11 & $0.000 \mathrm{E}$ & 0.003 & $2.082^{*}$ & $2.039^{*}$ & $3.906^{*}$ & $4.906^{*}$ & $4.952^{*}$ & $7.236^{*}$ & $11.678^{*}$ & $12.280^{*}$ \\
\hline Erro & 24 & $0.000 \mathrm{E}$ & 0.002 & 0.097 & 0.290 & 0.483 & 0.429 & 0.375 & 0.399 & 0.172 & 0.357 \\
\hline CV\% & & 0.00 & 25.54 & 19.09 & 22.92 & 23.03 & 17.51 & 14.22 & 11.20 & 6.10 & 8.52 \\
\hline
\end{tabular}

* Significativo pelo teste $\mathrm{F}$ ao nível de $5 \%$ de probabilidade.

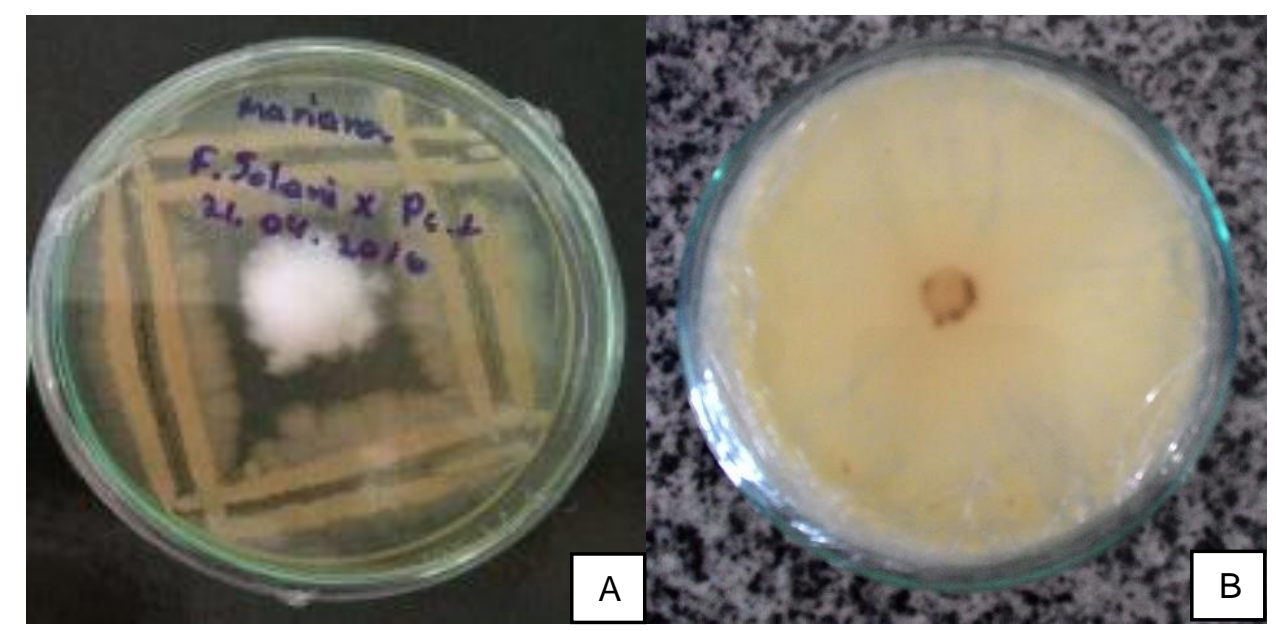

Figura 3. Comparação entre placa de Petri com bactéria $x$ fungo e a testemunha, ambas com 10 dias de inoculação: A - Bactéria P6.2 inibindo o desenvolvimento do F. solani; B - Testemunha do F. solani. Fonte: JESUS, M. S. 
Tabela 3. Diâmetros das colônias $(\mathrm{cm})$ do $1^{\circ}$ ao $10^{\circ}$ dia de interação in vitro entre o fungo Fusarium solani e as bactérias analisadas, desenvolvido em Euclides da Cunha, BA, 2016.

\begin{tabular}{|c|c|c|c|c|c|c|c|c|c|c|}
\hline \multirow[t]{2}{*}{ Bactérias } & \multicolumn{10}{|c|}{ Médias do diâmetro das colônias do $1^{\circ}$ ao $10^{\circ}$ dia } \\
\hline & $1^{\circ}$ & $2^{\circ}$ & $3^{\circ}$ & $4^{\circ}$ & $5^{\circ}$ & $6^{\circ}$ & $7^{\circ}$ & $8^{\circ}$ & $9^{\circ}$ & $10^{\circ}$ \\
\hline Testemunha & -- & $\begin{array}{c}0.200 \\
\mathrm{~A} 1\end{array}$ & $\begin{array}{c}2.966 \\
\text { A5 }\end{array}$ & $\begin{array}{c}3.916 \\
\text { A3 }\end{array}$ & $\begin{array}{c}5.466 \\
\text { A4 }\end{array}$ & $\begin{array}{c}5.816 \\
\text { A4 }\end{array}$ & $\begin{array}{c}6.233 \\
\text { A4 }\end{array}$ & $\begin{array}{c}8.166 \\
\text { A4 }\end{array}$ & $\begin{array}{c}8.733 \\
\text { A4 }\end{array}$ & $\begin{array}{c}9.000 \\
\text { A3 }\end{array}$ \\
\hline P2.2 & -- & $\begin{array}{c}0.250 \\
\mathrm{~A} 1\end{array}$ & $\begin{array}{c}1.966 \\
\text { A4 }\end{array}$ & $\begin{array}{c}2.716 \\
\text { A2 }\end{array}$ & $\begin{array}{c}3.533 \\
\text { A3 }\end{array}$ & $\begin{array}{c}4.150 \\
\text { A3 }\end{array}$ & $\begin{array}{c}4.716 \\
\text { A2 }\end{array}$ & $\begin{array}{c}5.233 \\
\text { A2 }\end{array}$ & $\begin{array}{c}5.466 \\
\text { A2 }\end{array}$ & $\begin{array}{c}5.933 \\
\text { A2 }\end{array}$ \\
\hline P6.2 & -- & $\begin{array}{c}0.150 \\
\text { A1 }\end{array}$ & $\begin{array}{c}0.316 \\
\mathrm{~A} 1\end{array}$ & $\begin{array}{c}0.750 \\
\text { A1 }\end{array}$ & $\begin{array}{c}0.800 \\
\text { A1 }\end{array}$ & $\begin{array}{c}1.267 \\
\mathrm{~A} 1\end{array}$ & $\begin{array}{c}1.483 \\
\mathrm{~A} 1\end{array}$ & $\begin{array}{c}1.683 \\
\text { A1 }\end{array}$ & $\begin{array}{c}1.867 \\
\mathrm{~A} 1\end{array}$ & $\begin{array}{c}1.933 \\
\mathrm{~A} 1\end{array}$ \\
\hline P7.2 & -- & $\begin{array}{c}0.150 \\
\mathrm{~A} 1\end{array}$ & $\begin{array}{c}1.367 \\
\text { A3 }\end{array}$ & $\begin{array}{c}2.117 \\
\text { A2 }\end{array}$ & $\begin{array}{c}2.617 \\
\text { A2 }\end{array}$ & $\begin{array}{c}3.233 \\
\text { A2 }\end{array}$ & $\begin{array}{c}3.950 \\
\text { A2 }\end{array}$ & $\begin{array}{c}5.833 \\
\text { A2 }\end{array}$ & $\begin{array}{c}8.317 \\
\text { A4 }\end{array}$ & $\begin{array}{c}8.450 \\
\text { A3 }\end{array}$ \\
\hline P8.2 & -- & $\begin{array}{c}0.183 \\
\mathrm{~A} 1\end{array}$ & $\begin{array}{c}1.683 \\
\text { A3 }\end{array}$ & $\begin{array}{c}2.217 \\
\text { A2 }\end{array}$ & $\begin{array}{c}2.633 \\
\text { A2 }\end{array}$ & $\begin{array}{c}3.150 \\
\text { A2 }\end{array}$ & $\begin{array}{c}4.333 \\
\text { A2 }\end{array}$ & $\begin{array}{c}6.750 \\
\text { A3 }\end{array}$ & $\begin{array}{c}8.567 \\
\text { A4 }\end{array}$ & $\begin{array}{c}8.633 \\
\text { A3 }\end{array}$ \\
\hline P9.2 & -- & $\begin{array}{c}0.217 \\
\mathrm{~A} 1\end{array}$ & $\begin{array}{c}1.450 \\
\mathrm{~A} 1\end{array}$ & $\begin{array}{c}2.117 \\
\text { A2 }\end{array}$ & $\begin{array}{c}2.733 \\
\text { A2 }\end{array}$ & $\begin{array}{c}3.750 \\
\text { A2 }\end{array}$ & $\begin{array}{c}4.266 \\
\text { A2 }\end{array}$ & $\begin{array}{c}6.133 \\
\text { A2 }\end{array}$ & $\begin{array}{c}7.750 \\
\text { A4 }\end{array}$ & $\begin{array}{c}7.850 \\
\text { A3 }\end{array}$ \\
\hline P10.2 & -- & $\begin{array}{c}0.216 \\
\mathrm{~A} 1\end{array}$ & $\begin{array}{c}3.250 \\
\text { A5 }\end{array}$ & $\begin{array}{c}3.383 \\
\text { A3 }\end{array}$ & $\begin{array}{c}3.950 \\
\text { A3 }\end{array}$ & $\begin{array}{c}4.366 \\
\text { A3 }\end{array}$ & $\begin{array}{c}3.933 \\
\text { A2 }\end{array}$ & $\begin{array}{c}5.033 \\
\text { A2 }\end{array}$ & $\begin{array}{c}5.400 \\
\text { A2 }\end{array}$ & $\begin{array}{c}5.333 \\
\text { A2 }\end{array}$ \\
\hline P11.2 & -- & $\begin{array}{c}0.150 \\
\mathrm{~A} 1\end{array}$ & $\begin{array}{c}1.366 \\
\text { A3 }\end{array}$ & $\begin{array}{c}2.600 \\
\text { A2 }\end{array}$ & $\begin{array}{c}3.750 \\
\text { A3 }\end{array}$ & $\begin{array}{c}5.800 \\
\text { A4 }\end{array}$ & $\begin{array}{c}6.383 \\
\text { A4 }\end{array}$ & $\begin{array}{c}6.733 \\
\text { A3 }\end{array}$ & $\begin{array}{c}7.000 \\
\text { A3 }\end{array}$ & $\begin{array}{c}7.700 \\
\text { A3 }\end{array}$ \\
\hline P12.2 & -- & $\begin{array}{c}0.216 \\
\mathrm{~A} 1\end{array}$ & $\begin{array}{c}2.050 \\
\text { A4 }\end{array}$ & $\begin{array}{c}2.333 \\
\text { A2 }\end{array}$ & $\begin{array}{c}3.333 \\
\text { A3 }\end{array}$ & $\begin{array}{c}4.200 \\
\text { A3 }\end{array}$ & $\begin{array}{c}4.966 \\
\text { A3 }\end{array}$ & $\begin{array}{c}5.766 \\
\text { A2 }\end{array}$ & $\begin{array}{c}5.866 \\
\text { A2 }\end{array}$ & $\begin{array}{c}5.966 \\
\text { A2 }\end{array}$ \\
\hline P13.2 & -- & $\begin{array}{c}0.200 \\
\mathrm{~A} 1\end{array}$ & $\begin{array}{c}1.133 \\
\text { A2 }\end{array}$ & $\begin{array}{c}2.350 \\
\text { A2 }\end{array}$ & $\begin{array}{c}2.633 \\
\text { A2 }\end{array}$ & $\begin{array}{c}3.183 \\
\text { A2 }\end{array}$ & $\begin{array}{c}3.850 \\
\text { A2 }\end{array}$ & $\begin{array}{c}5.133 \\
\text { A2 }\end{array}$ & $\begin{array}{c}6.433 \\
\text { A3 }\end{array}$ & $\begin{array}{c}6.500 \\
\text { A2 }\end{array}$ \\
\hline CF17.2 & -- & $\begin{array}{c}0.166 \\
\text { A1 }\end{array}$ & $\begin{array}{c}1.150 \\
\text { A2 }\end{array}$ & $\begin{array}{c}2.416 \\
\mathrm{~A} 2\end{array}$ & $\begin{array}{c}2.766 \\
\text { A2 }\end{array}$ & $\begin{array}{c}3.516 \\
\text { A2 }\end{array}$ & $\begin{array}{c}4.316 \\
\mathrm{~A} 2\end{array}$ & $\begin{array}{c}6.316 \\
\text { A3 }\end{array}$ & $\begin{array}{c}8.000 \\
\text { A4 }\end{array}$ & $\begin{array}{c}8.300000 \\
\text { A3 }\end{array}$ \\
\hline CF20.2 & -- & $\begin{array}{c}0.250 \\
\mathrm{~A} 1\end{array}$ & $\begin{array}{c}0.883 \\
\text { A2 }\end{array}$ & $\begin{array}{c}1.316 \\
\mathrm{~A} 1\end{array}$ & $\begin{array}{c}2.000 \\
\text { A2 }\end{array}$ & $\begin{array}{c}2.483 \\
\text { A2 }\end{array}$ & $\begin{array}{c}3.266 \\
\text { A2 }\end{array}$ & $\begin{array}{c}4.916 \\
\mathrm{~A} 2 \\
\end{array}$ & $\begin{array}{c}8.283 \\
\text { A4 }\end{array}$ & $\begin{array}{c}8.566 \\
\text { A3 }\end{array}$ \\
\hline
\end{tabular}

${ }^{*}$ Médias seguidas de mesma letra e número, na coluna, não diferem entre si pelo teste de ScottKnott a 5\% de significância.

Trabalhos anteriores desenvolvidos por Pusey e Wilson (1984) demonstraram que diversos isolados de espécies de Bacillus tem a capacidade de inibir o crescimento dos fungos de diversas culturas, como foi observado neste experimento, onde a Bactéria P6.2 conseguiu inibir visivelmente o antagonista pela formação do halo de inibição, que se manifesta como uma limitação do crescimento do fungo pela bactéria. Mecanismos de diminuição ou estagnação do crescimento micelial do inóculo podem ser atribuídos a hiperparasitismo, estimulo a germinação de propágulos

Revista Ouricuri, Juazeiro, Bahia, v.8, n.1. p.048-056.jan./jun., 2018. 
com consequente exaustão, antibiose ou predação (GHINI et al., 2001), isto pode ser a causa da inibição do crescimento do F. Solani.

Outras bactérias também conseguiram retardar o crescimento do fungo em uma menor proporção, são elas as P2.2, P10.2, P12.2 e P13.2, tendo um resultado semelhante a P6.2, onde conseguiram inibir o fungo desde o $3^{\circ}$ dia, só que inferior a P6.2 segundo a análise estatística (Tabela 3). Muitos trabalhos relatam o grande potencial de espécies de Bacillus no controle de patógenos do solo especialmente espécies de Fusarium (JENNY e GROSSEMBACHER, 1963; MICHAEL e NELSON, 1972; FILIPPI et al., 1987;). Segundo Van Peer et al. (1991) a produção de ácido hidrociânico (HCN) pelas RPCPs aparenta ser um fenômeno bastante comum. Este metabólito que é originado da glicina, apresenta potencial de inibir vários patógenos. Outro mecanismo muito eficiente no controle dos fungos também é o composto 2,4 diacetilfloroglucinol (Phl), devido ele conseguir inibir o crescimento dos fungos.

Já as rizobactérias P7.2, P8.2, P9.2, P11.2, CF17.2 e a CF20.2, por mais que tenham conseguido inibir o fungo em algum dos dias analisados durante o desenvolvimento, no último dia de análise foi constado que a sua inibição foi igual ou inferior à testemunha. As bactérias testadas devem produzir algum metabólito que iniba o crescimento deste fungo. Muitos autores relatam que as rizobactérias conseguem produzir uma grande variedade de antibióticos, como: pioluteorinas, pirrolnitrinas, tropolonas, piocianinas e 2,4 diacetilfloroglucinol (CAMPBELL et al., 1993). Há antibióticos produzidos por bactérias que atuam nos fungos através de mecanismos que inibem o seu crescimento micelial (DILDEY et al., 2014).

A partir destes resultados pode-se constatar que o controle biológico do F. sonali a partir da utilização dessas rizobactérias é eficiente, quando testados in vitro. O controle biológico acontece quando dois microrganismos ao longo de sua vida, se desenvolvem simultaneamente, e um sobrepõe o desenvolvimento do outro, competindo de forma direta por alimento ou indireta com a liberação de substâncias que serão tóxicas para o outro indivíduo (BELL et al., 1982).

\section{CONCLUSÕES}

A rizobactéria P6.2 foi a que apresentou um melhor resultado estatístico no controle do $F$. solani, onde conseguiu inibir o fungo durante os dias analisados.

As rizobactérias P2.2, P10.2, P12.2 e P13.2 conseguiram inibir o fungo em menor intensidade.

Aconselha-se que realizem testes in vivo, para que se confirme o resultado realizado in vitro.

\section{AGRADECIMENTOS}

Agradeço a UNEB Campus XXII, ao LAMSA. 


\section{REFERÊNCIAS}

AMORIM, L.; REZENDE, J. A. M.; BERGAMIN FILHO, A. Manual de fitopatologia: princípios e conceitos. 4. ed. São Paulo: Agronômica Ceres, 543-589, 2011.

ANTOUN, H., BEAUCHAMP, C. J.; GOUSSARD, N.; CHABOT, R.; LALANDE, R. Potential of Rhizobium and Bradyrhizobium species as plant growth promoting rhizobacteria on no-legumes: Effect on radishes (Raphanus sativus L.). Plant and Soil, 204(1), 57-67, 1998.

BELL, D. K.; WELLS, H. D.; MARKHAM, C. R. In vitro antagonism of trichoderma species against six fungal plant pathogens. Ecology and Epidemiology, 72(4), 379-382, 1982.

BETTIOL, W. Controle biológico de doenças de plantas. Jaguariúna: EMBRAPA-CNPDA, 1991. 226 p.

BONFIM, M. P.; SÃO JOSÉ, A. B.; REBOUÇAS, T. N. H.; ALMEIDA, S. S.; SOUZA, I. V. B.; DIAS, N. O. Avaliação antagônica in vitro e in vivo de trichoderma spp. a rhizopus stolonifer em maracujazeiro amarelo. Summa Phytopathologica, 36(1), 61-67, 2010.

CAMPBELL, J. P.; MCCLOY, R. A.; OPPLER, S. H.; SAGER, C. E. 'A theory of performance', in C. W. Schmitt and W. C. A. Borman (eds), Personnel Selection in Organizations. San Francisco: Jossey Bass. p. 35-70, 1993.

CREPPY, E. E. Update of survey, regulation and toxic effects of mycotoxins in Europe. Toxicology Letters, Amsterdam, 127(1-3), 19-28, 2002.

DASHTI, N. Plant growth promoting rhizobacteria accelerate nodulation and increase nitrogen fixation activity by field grown soybean (Glycine max L. Merr) under short season conditions. Plant and Soil, 200, 205-213, 1998.

DILDEY, O. D. F.; BARBIAN, J. M.; GONÇALVES, E. D. V.; BROETTO, L.; ETHUR, L. Z.; KUHN, O. J.; BONETT, L. P. Inibição do crescimento in vitro de sclerotinia sclerotiorum, causador de mofo branco, por isolados de trichoderma spp. Revista Brasileira de Biociência, 12(3), 132-136, 2014.

FILIPPI, C.; BAGNOLI, G.; VOLTERRANI, M.; PICCI, G. Antagonistic effects of soil bacteria on Fusarium oxysporum f. sp. dianth (Prill and Del.) Snyd. and Hans. Plant and Soil, 98(2), 161-167, 1987.

GHINI, R.; NAKAMURA, D. Seleção de antagonistas e nutrientes que induzem supressividade de solos a Fusarium oxysporumf. sp. Phaseoli em microcosmos e in vivo. Summa Phytopathologica, 27(3), 318-322, 2001.

GRAY, E. J.; SMITH, D. L. Intracellular and extracelular PGPR: commonalities and distinctions in the plant-bacterium signaling processes. Soil Biology and Biochemistry, 37, 395-412, 2005.

JENNY, H.; GROSSEMBACHER, K. Root soil boundary zones as seen in the electron microscope. Soil Science Society of America Journal, 27(3), 273-277, 1963.

KIMATI, H.; GIMENEZ-FERNANDES, N.; SOAVE, J.; KUROZAWA, C.; BRIGNANI NETO, F.; BETTIOL, W. Guia de Fungicidas Agrícolas - Recomendações por Cultura, v. 1, $2^{2}$ ed. Jaboticabal: Grupo Paulista de Fitopatologia, 225 p. 1997.

MICHAEL, A. H.; NELSON, P. E. Antagonistic Effect of Soil Bacteria on Fusanum roseum "Culmorum" from Carnation. Phytopathology, 62, 1052-1056, 1972.

PASCHOLATI, S. F. Fisiologia do parasitismo: como os patógenos atacam as plantas. In Amorim, L.; Rezende, J.A.M.; Bergamin Filho, A. (eds.). Manual de fitopatologia: princípios e conceitos. 4. ed. São Paulo: Agronômica Ceres, p. 543-589, 2011.

Revista Ouricuri, Juazeiro, Bahia, v.8, n.1. p.048-056.jan./jun., 2018. 
PERES, F.; MOREIRA, J. C. Saúde e ambiente em sua relação com o consumo de agrotóxicos em um pólo agrícola do estado do Rio de Janeiro, Brasil. Caderno Saúde Pública, Rio de Janeiro, v. 23(4), 5612-5621, 2007.

PUSEY, P. L.; WILSON, C. L. Postharvest biological control of stone fruit brown rot by Bacillus subtilis. Plant Disease, 68(9), 753-756, 1984.

SCHROTH, M. N.; HANCOCK, J. Disease suppressive soil and root colonizing bacteria. Science, 216(4553), 1376-1381, 1982.

SESSITSCH, A.; KUFFNER, M.; KIDD, P.; VANGRONSVELD, J.; WENZEL, W. W.; FALLMANN, K.; PUSCHENREITER, M. The role of plant-associated bacteria in the mobilization and phytoextraction of trace elements in contaminated soils. Soil Biology and Biochemistry, 60(100), 182-194, 2013.

SINGH, K.; FRISVAD, J. C.; THRANE, U.; MATHUR, S. B. An illustrated manual on identification of some seed-born Aspergilli, Fusaria, Penicillia and their micotoxins. Hellerup: Danish Government Institute of Seed Pathology for Developing Countries, $1981.133 p$.

TREMACOLDI, C. R. Principais doenças fúngicas da pimenteira-do-reino no Estado do Pará e recomendações de controle. Belém. Embrapa Amazônia Oriental. 2010. 23 p. (Documentos, 367).

VAN PEER, R.; NIEMANN, G. J.; SCHIPPERS, B. Induced resistance and phytoalexin accumulation in biological control of Fusarium wilt of carnation by Pseudomonas sp. Strain WCS417r. Phytopathology, 728-734, 1991.

VEGA-HERNÁNDEZ, M. C.; LEON-BARRIOS, M.; PÉREZ-GALDONA, R. Indole-3- acetic acid production from indole-3-acetonitrile in Bradyrhizobium. Soil Biology and Biochemistry, 34, 665-668, 2002.

WELLER, D. M. Biological control of rhizosphere with bacteria. Annual Review of Phytopathology, 26, 379-407, 1988. 